\title{
Silencing of Neuroligin Function by Postsynaptic Neurexins
}

\author{
Hiroki Taniguchi, ${ }^{1}$ Leora Gollan, ${ }^{1}$ Francisco G. Scholl, ${ }^{1}$ Veeravan Mahadomrongkul, ${ }^{2}$ Elizabeth Dobler, ${ }^{2}$ \\ Nicolas Limthong, ${ }^{1}$ Morgen Peck, ${ }^{1}$ Chiye Aoki, ${ }^{2}$ and Peter Scheiffele ${ }^{1}$ \\ ${ }^{1}$ Department of Physiology and Cellular Biophysics, Center for Neurobiology and Behavior, Columbia University, Physicians and Surgeons 11-511, New \\ York, New York 10032, and ${ }^{2}$ Center for Neural Science, New York University, New York, New York 10003
}

\begin{abstract}
The formation of neuronal circuits during development involves a combination of synapse stabilization and elimination events. Synaptic adhesion molecules are thought to play an important role in synaptogenesis, and several trans-synaptic adhesion systems that promote the formation and maturation of synapses have been identified. The neuroligin-neurexin complex is a heterophilic adhesion system that promotes assembly and maturation of synapses through bidirectional signaling. In this protein complex, postsynaptic neuroligins are thought to interact trans-synaptically with presynaptic neurexins. However, the subcellular localization of neurexins has not been determined. Using immunoelectron microscopy, we found that endogenous neurexins and epitope-tagged neurexin- $1 \beta$ are localized to axons and presynaptic terminals in vivo. Unexpectedly, neurexins are also abundant in the postsynaptic density. cis-expression of neurexin-1 $\beta$ with neuroligin-1 inhibits trans-binding to recombinant neurexins, blocks the synaptogenic activity of neuroligin-1, and reduces the density of presynaptic terminals in cultured hippocampal neurons. Our results demonstrate that the function of neurexin proteins is more diverse than previously anticipated and suggest that postsynaptic cis-interactions might provide a novel mechanism for silencing the activity of a synaptic adhesion complex.
\end{abstract}

Key words: synapse formation; hippocampus; adhesion; neuroligin; neurexin; hippocampal neurons

\section{Introduction}

Central synapses are specialized cell-cell junctions that relay information between neurons. The highly organized presynaptic and postsynaptic domains are linked through trans-synaptic adhesion complexes (Fannon and Colman, 1996; Yamagata et al., 2003). Although adhesive interactions provide synaptic junctions with a remarkable mechanical stability, synapses nevertheless can dynamically change their size and can be rapidly eliminated (Goda and Davis, 2003). This implies that mechanisms must exist that weaken synaptic adhesion complexes and lead to their disassembly.

Recent studies identified several adhesion molecules that might contribute to the assembly and stability of synapses, in-

\footnotetext{
Received June 7, 2006; revised Feb. 2, 2007; accepted Feb. 2, 2007.

This work was supported by awards from The John Merck Fund, the Irma T. Hirschl Trust, the Simons Foundation, and National Institutes of Health Grant R01 NS045014 (P.S.), and National Institutes of Health Grants R01-NS41091 and R01-EY13145 and the New York University Research Challenge Fund (C.A.). H.T. was supported by a Toyobo Biofoundation long-term research fellowship, and L.G. is the recipient of an EMBO long-term fellowship and a senior postdoctoral fellowship from the Charles H. Revson Foundation. We thank Drs. Asim Beg and Karen Wu for comments on this manuscript, Dr. Thomas Jessell, Jennifer Kirkland, and Monica Mendelsohn for generous help with the generation of transgenic mice, Dr. Pico Caroni for sharing the Thy1.2 promoter cassette, Drs. Fiona Doetsch and Hynek Wichterle for sharing equipment, and Dr. Michael Greenberg for EphB2 CDNA.

Correspondence should be addressed to Peter Scheiffele, Columbia University, Department of Physiology and Cellular Biophysics, 630 West 168th Street, Physicians and Surgeons 11-511, New York, NY 10032. E-mail: ps2018@columbia.edu.

H. Taniguchi's present address: Cold Spring Harbor Laboratory, Beckman 220, One Bungtown Road, Cold Spring Harbor, NY 11724.

F. G. Scholl's present address: Department of Physiology and Biophysics, School of Medicine, University of Seville, Avenida Sánchez Pizjúan, 4, 41009 Seville, Spain.

V. Mahadomrongkul's present address: Department of Neuroscience, Albert Einstein Medical College, Yeshiva University, 1300 Morris Park Avenue, Bronx, NY 10461.

D01:10.1523/JNEUROSCI.0032-07.2007

Copyright $\odot 2007$ Society for Neuroscience $\quad 0270-6474 / 07 / 272815-10 \$ 15.00 / 0$
}

cluding the neuroligin-neurexin complex (Benson et al., 2001; Scheiffele, 2003; Waites et al., 2005). Neuroligins (NL1-NL4) are postsynaptic proteins containing an extracellular cholinesterase domain (Song et al., 1999). Neurexins (NRX1-NRX3) are presumptive axonal receptors that bind to neuroligins through an extracellular LNS (laminin-neurexin-sex-hormone-binding protein) domain. Each neurexin gene gives rise to $\alpha$ and $\beta$ isoforms that exhibit differential interaction with neuroligins, and interactions are further regulated through alternative splicing (Ichtchenko et al., 1995; Boucard et al., 2005; Chih et al., 2006; Graf et al., 2006).

Functional in vitro assays revealed that the neuroligin-neurexin complex has potent synaptogenic activities: NL1 expressed in non-neuronal cells or overexpression in cultured neurons triggers the assembly of presynaptic elements (Scheiffele et al., 2000; Dean et al., 2003), whereas disruption of neuroligin function perturbs synaptic differentiation (Scheiffele et al., 2000; Graf et al., 2004; Prange et al., 2004; Chih et al., 2005; Levinson et al., 2005; Nam and Chen, 2005). Mice lacking all three major neuroligin isoforms die at birth. Although anatomical studies of neuroligin triple knock-out mice reveal only moderate changes on the structural level, there are severe defects in synaptic transmission (Varoqueaux et al., 2006). This suggests that loss of some of the structural synapse assembly activities of neuroligins can be compensated but that neuroligins are essential for the formation of functional synaptic connections.

All current models of the neuroligin-neurexin complex rely on the presynaptic localization of neurexins, but several findings have challenged this view. In electric ray, neurexins were suggested to be present in axons but absent from synapses (Russell and Carlson, 1997). Cortical neurons lacking all $\alpha$-neurexins 
show defects in postsynaptic glutamate receptor function (Kattenstroth et al., 2004), and neurexins are enriched in postsynaptic density (PSD) preparations (Peng et al., 2004). Resolving these discrepancies requires ultrastructural studies of neurexin localization, which have not been performed. If neurexins were localized to the postsynaptic compartment, then a puzzling question is whether coexistence of the neurexin-neuroligin pair within the same membrane leads to cis-interactions.

We examined the subcellular localization of neurexins in vivo. Our results confirm the presynaptic localization of neurexins but also reveal an unexpected accumulation in the postsynaptic density. We probed the consequences of neurexin and neuroligin coexpression and found that cis-expressed $\beta$-neurexins inactivate NL1 and promote the destabilization of synapses. These findings reveal a candidate mechanism for the regulation of neuroligin activity and demonstrate that neurexin functions are more complex than previously anticipated.

\section{Materials and Methods}

DNA constructs. For expression experiments, cDNAs were inserted into the pCAGGS vector under control of the chicken $\beta$-actin promoter. Studies were performed with the NL1 splice isoform containing A and B insertions with a vesicular stomatitis virus (VSV) epitope tag inserted after the signal sequence. Transfected neurexin isoforms contained an hemagglutinin (HA) tag inserted after the signal peptide. An NRX1 $\alpha 4(-)$ cDNA was isolated by reverse transcription-PCR from an embryonic day 18 rat whole-brain cDNA preparation. In the NRX $\Delta$ LNS mutant, amino acids $109-233$ of NRX1 $\beta$, corresponding to the $\beta$ sheets $3-12$ within the LNS domain, were deleted. The construct encoding the neurexin-Fc fusion protein has been described previously (Scheiffele et al., 2000).

Generation of green fluorescent protein-neurexin mice. Green fluorescent protein (GFP)-NRX1 $\beta 4(+)$ containing a VSV epitope after the signal sequence (alanine 47) and the cDNA encoding enhanced GFP (EGFP) in the extracellular stalk region (Threonine 302) was introduced into a Thy1.2 expression cassette (Caroni, 1997). After linearization, the construct was introduced into fertilized eggs derived from B6CBAF1 mice by pronuclear injection. Pseudopregnant CD-1 outbred albino females were used as foster mothers for embryo transfer. Founder and transgenic mice were genotyped by PCR of tail genomic DNA, using primers derived from NRX1 $\beta$ cDNA and EGFP coding sequences. Founders were further crossed with B6CBAF1 mice to generate lines and backcrossed to C57BL/6. Quantitative PCR for measuring neurexin overexpression level were performed using a Light Cycler MX3000P with Brilliant SYBR Green (Stratagene, La Jolla, CA). NRX1 primers were used to amplify a product containing sequences of exons 19 and 20, and primers for $\beta$-actin were used as a normalization control.

Antibodies. Pan-neuroligin antibodies were raised against a recombinant protein containing the cytoplasmic tail of NL1 fused to glutathione $S$-transferase. Rabbit sera were affinity purified over a recombinant protein containing the same cytoplasmic tail fused to maltose-binding protein. Affinity-purified antibodies recognized NL1-NL4 isoforms with comparable affinity in Western blots (supplemental Fig. S3B, available at www.jneurosci.org as supplemental material). Anti-GFP antibodies were generated in rabbits and affinity purified using recombinant EGFP produced in Escherichia coli. Chicken anti-pan-neurexin antibodies have been described previously (Dean et al., 2003). Commercially available primary antibodies used in this study were as follows: mouse anticalbindin (Swant, Bellizona, Switzerland), chicken anti-GFP (Upstate Biotechnology, Lake Placid, NY), rabbit anti-vesicular glutamate transporter (vGlut1) (Synaptic Systems, Goettingen, Germany), mouse anti-PSD95 (Affinity BioReagents, Golden, CO), mouse anti-vesicleassociated membrane protein (VAMP2) (Synaptic Systems), mouse antiearly endosomal antigen 1 (EEA1) (BD Transduction Laboratories, Lexington, KY), rabbit anti-VSV (Stressgen, Victoria, British Columbia, Canada), and rat anti-HA (Roche, Indianapolis, IN). Highly crossabsorbed secondary antibodies raised in donkey and conjugated to cya- nine 2 (Cy2), Cy3, and $\mathrm{Cy} 5$ were used for multiple labeling experiments (Jackson ImmunoResearch, West Grove, PA). Antibodies for EM were as follows: biotinylated goat anti-rabbit IgGs and biotinylated goat antichicken IgGs (Vector Laboratories, Burlingame, CA), $0.8 \mathrm{~nm}$ goldconjugated goat anti-biotin IgG and $10 \mathrm{~nm}$ gold-conjugated goat antichicken IgG (Electron Microscoscopy Sciences/Aurion, Fort Washington, PA), and rabbit anti-GFP (Invitrogen, Carlsbad, CA).

Cell culture and transfection. For dissociated hippocampal cultures, tissue was dissected from embryonic day 18-19 rat brains, treated with $0.25 \%$ trypsin in DMEM with high glucose (Invitrogen) for $25 \mathrm{~min}$ at $37^{\circ} \mathrm{C}$, and was triturated by pipetting. Dissociated cells were plated on poly-D-lysine-coated glass coverslips at a density of $25,000 / \mathrm{cm}^{2}$ and maintained in neurobasal medium (Invitrogen) supplemented with 2 mм Glutamax (Invitrogen), B27 (Invitrogen), and penicillin/streptomycin (Invitrogen) at $37^{\circ} \mathrm{C}$ and $5 \% \mathrm{CO}_{2}$. Cells were transfected using Lipofectamine 2000 (Invitrogen) at 12-15 d in vitro (DIV) after plating and fixed 2-3 d after transfection (Dean and Scheiffele, 2004).

Human embryonic kidney (HEK293) cells were maintained in DMEM containing $10 \%$ fetal bovine serum and penicillin/streptomycin. Cells were transfected using Lipofectamine Plus (Invitrogen). For the mixed culture assay with HEK293 cells and hippocampal neurons, HEK293 cells were transfected for $3 \mathrm{~h}$ followed by dissociation with trypsin. The cell suspension was washed and resuspended in neurobasal medium, and cells were added into 10 DIV neuronal cultures at a density of $8,000 / \mathrm{cm}^{2}$ and maintained for $2 \mathrm{~d}$.

Light microscopy. Cultured cells were fixed with $4 \%$ paraformaldehyde (PFA) in phosphate buffer (PB) containing 4\% sucrose and were permeabilized and blocked with $10 \%$ normal goat serum in PBS containing $0.1 \%$ Triton X-100. For immunostaining with anti-PSD95 antibodies, cells were first fixed with 4\% PFA for $5 \mathrm{~min}$, followed by methanol fixation. Cells were incubated with primary and secondary antibodies for $2-24 \mathrm{~h}$ in the same blocking solution. Cell surface staining was performed by incubating cells with primary antibodies without permeabilization.

For analysis of GFP-NRX1 $\beta 4(+)$ mice, animals were perfused with $4 \%$ paraformaldehyde in PBS. Brains were isolated and incubated in the same fixative overnight. Then tissues were cut into $30 \mu \mathrm{m}$ sections using vibratome (Leica, Nussloch, Germany). Sections were blocked and permeabilized in 5\% BSA and $0.5 \%$ Triton X-100 in PBS for $1 \mathrm{~h}$ at room temperature. Antibodies were diluted in 5\% BSA and $0.05 \%$ Triton $\mathrm{X}-100$ in PBS. Primary antibody incubation was $3 \mathrm{~h}$ at room temperature or overnight at $4^{\circ} \mathrm{C}$. Secondary antibody incubation was for $1 \mathrm{~h}$ at room temperature. Sections were mounted and analyzed by fluorescence microscopy.

Preparation of tissue for electron microscopic immunocytochemistry. A pan-NRX antibody directed against the conserved cytoplasmic tail of neurexins (Dean et al., 2003) was used to localize neurexins within intact tissue of rat brains. Three adult and three postnatal day 7 (P7) Wistar rats were transcardially perfused with a mixture of aldehydes to fix the brain. All fixatives contained $0.1 \mathrm{M} \mathrm{PB}, \mathrm{pH} 7.4$, and $4 \%$ paraformaldehyde. This was supplemented with $1 \%$ glutaraldehyde or $3 \%$ acrolein or neither. Slabs of brains were sectioned in the sagittal or coronal plane, using a vibratome, and fixation was terminated by reacting free-floating sections with $1 \%$ sodium borohydride made in $0.1 \mathrm{M} \mathrm{PB}$. Sections were stored at $5^{\circ} \mathrm{C}$, free floating in a solution consisting of $0.9 \%$ sodium chloride (saline), $0.01 \mathrm{~m}$ phosphate buffer, $\mathrm{pH} 7.4$, and $0.05 \%$ sodium azide (PBSazide) to prevent bacterial growth. Antigenic sites were localized using one of two different electron-dense immunolabels: horseradish peroxidase-diaminobenzidine (HRP-DAB) reaction product for pre-embed immunolabeling and $10 \mathrm{~nm}$ colloidal gold particles for post-embed immunogold (PEG) labeling. HRP-DAB reaction product was used to maximize detection of neurexin. PEG was used to optimize detection of the antigen at the synaptic junction. For the pre-embed immunolabeling procedure, tissue was first permeabilized by repeated freeze-thawing and then treated with $1 \%$ hydrogen peroxide in PBS for antigen retrieval. The chicken anti-pan-NRX (Dean et al., 2003) was applied by gentle tumbling of free-floating vibratome sections in PBS-azide containing the antibody at a dilution of 1:75 or 1:120 and 1\% bovine serum albumin to minimize background labeling. The incubation period was for $3 \mathrm{~d}$ at room temperature. Additional fixation of vibratome sections with $1 \%$ 
osmium tetroxide was performed at the end of the immunocytochemical procedure. For control, free-floating sections were incubated identically, except that the $3 \mathrm{~d}$ incubation was performed using a pan-NRX primary antibody that had been preadsorbed by the neurexin-1-maltose binding protein fusion protein used to affinity purify the antibody. This control condition yielded no labeling over synapses (see Fig. $1 B$ ) (supplemental Fig. S1 $A, B$, available at www.jneurosci.org as supplemental material).

For PEG, the pan-NRX primary antibody was applied to ultrathin sections mounted on Formvar-coated grids at a dilution of 1:25 overnight at room temperature. These ultrathin sections were collected from vibratome sections of brains that were fixed by transcardial perfusion with $4 \%$ paraformaldehyde and $1 \%$ glutaraldehyde, followed by $1 \%$ osmium tetroxide fixation of vibratome sections. For PEG controls, grids were incubated overnight in the same buffer but with the primary antibody omitted. Similar results were obtained with pan-NRX antibodies isolated from two different animals that had been immunized with the neurexin antigen, whereas controls showed complete elimination of labeling over synapses and axons.

Anti-GFP antibodies for detection of GFP-NRX in transgenic mice were used at a dilution ranging from 1:2000 up to 1:6000. Two preembed immunolabeling procedures were used: HRP-DAB reaction product to maximize detection of GFP-NRX and silver-intensified gold (SIG) to distinguish and quantify the membranous versus intracellular sites of the antigen. For both procedures, the immunolabeling of wildtype littermates of the transgenic mice served as controls (supplemental Fig. S1C, available at www.jneurosci.org as supplemental material). Vibratome sections of transgenic and wild-type mice were collected from brains fixed by transcardial perfusion with $4 \%$ paraformaldehyde. The HRP-DAB-labeled vibratome sections were further fixed with $1 \%$ osmium tetroxide, whereas the SIG-labeled vibratome sections were fixed using Phend's osmium-free tissue fixation method.

Additional details of steps for generating the three electron-dense labels (SIG, HRP-DAB, and PEG) were as described previously (Phend et al., 1995; Aoki et al., 2001, 2005).

Image acquisition and quantification. All quantitations were performed for at least three independent experiments. In each single experiment, at least 10 cells were quantitatively analyzed per condition. Images for each experiment were acquired using a Zeiss (Oberkochen, Germany) LSM510 confocal microscope using the same settings for laser power, gain, and offset for all images. Projections of $Z$-stacked images were analyzed by MetaMorph software (Molecular Devices, Palo Alto, CA). For neuroligin-neurexin coexpression studies, neuroligin-positive areas were selected by thresholding using the same threshold for all images. The threshold was set such that most of the specific neuroligin signal was selected, even in cells with low expression level. The outlines of neuroligin-positive regions were transferred into the VAMP2 channel, and the average staining intensity of VAMP2 was calculated. For experiments in which different neurexin constructs and EGFP were expressed in neurons, the GFP-expressing regions of $50 \mu \mathrm{m}$ dendritic segments were selected by thresholding. The outlines of GFP regions were imported into the vGlutl channel. The outlines of the GFP signal were modified such that also vGlut1 puncta only partially overlapping with the GFP area were fully included into the analysis. Using these modified regions, the total area of vGlut 1 with staining intensity above threshold was measured.

For NRX1 $\beta 4(-)-F c$ binding assays, regions representing the HEK293 cells and/or $50 \mu \mathrm{m}$ dendritic segments were determined by thresholding. Then the average NRX1 $\beta 4(-)-F c$ staining intensity and total area with staining intensity above a threshold was calculated. For experiments in which neurons expressing different neurexin constructs were stained with pan-NL antibodies, the neurexin-positive regions in $50 \mu \mathrm{m}$ dendritic segments were determined by thresholding, and within these regions average staining intensity for pan-neuroligin was calculated. Statistical analysis was performed using ANOVA followed by Dunnett's multiple comparison test.

EM images were acquired digitally, using the AMT (Perth, West Australia, Australia) software and Hamamatsu (Bridgewater, NJ) CCD camera or using EM negatives. For pre-embed immunolabeled materials, antigenic sites were categorized as residing over the plasma membrane versus intracellular portions of axons of dendrites or somata and presynaptically or postsynaptically. For post-embed immunolabeled materials, the antigenic sites labeled with PEG particles were quantified as follows. All PEG particles at labeled synapses (identified by PEG labeling within $\pm 50 \mathrm{~nm}$ from the postsynaptic membrane) were counted and grouped into bins according their distance from the postsynaptic membrane. Figure $1 F$ shows the number of gold particles within $0-10,10-20,20-30$ $\mathrm{nm}$, etc., from the postsynaptic membrane. Student's $t$ test was performed to determine whether the total and subcellular distribution of SIG or PEG particles reflecting antigenic sites differed significantly from control conditions. All statistical analyses revealed highly significant differences $(p<0.001)$.

Soluble neurexin binding assay. Soluble neurexin was produced in HEK293 cells transfected with pCAGGS driving expression of an NRX1 $\beta 4(-)-F c$ fusion protein as described previously (Scheiffele et al., 2000 ). For the neuronal binding assays, purified soluble neurexin was used at a concentration of $5 \mu \mathrm{g} / \mathrm{ml}$ in neurobasal medium.

HEK293 cells or hippocampal neurons were washed in medium $(5 \mathrm{~mm}$ $\mathrm{CaCl}_{2}$ in DMEM or neurobasal, respectively) and incubated with soluble neurexin for $20 \mathrm{~min}$ at $20^{\circ} \mathrm{C}$. After washing with medium, the cells were fixed with $4 \%$ PFA, and bound protein was detected by immunohistochemistry in nonpermeabilized cells.

\section{Results}

\section{Neurexins are localized presynaptically and postsynaptically} in vivo

To directly investigate the distribution of endogenous neurexins by immunoelectron microscopy, we used a pan-neurexin antibody directed against the conserved cytoplasmic tail of neurexins, which cross-reacts with the majority of $\alpha$ - and $\beta$-neurexin isoforms (Dean et al., 2003). Immunoelectron microscopy with these antibodies performed with HRP-DAB detection on postnatal day 7 rat cerebellum, cortex, and hippocampus revealed strong neurexin immunoreactivity in the endoplasmic reticulum of neurons, on axonal growth cones, preterminal portions of axons, and synaptic structures (Fig. $1 A$ and data not shown). Similar labeling was observed with the affinity-purified antibody preparations obtained from two different immunized animals, and labeling was lost when primary antibodies were omitted or were cross-absorbed with the antigen before incubation with the tissue (Fig. $1 B$ ) (supplemental Fig. S1. available at www.jneurosci.org as supplemental material).

To optimize immunolabeling of antigens at the synaptic junction, PEG labeling was performed. At synapses of P7 and P8 cerebral cortex, gold particles decorated the presynaptic active zones (Fig. $1 C$ ) and vesicular structures in the preterminal portions of axons. Surprisingly, we also observed prominent labeling of postsynaptic structures. Gold particles were observed clustered directly at the postsynaptic membrane, over the postsynaptic density, and inside the postsynaptic spine, including the intracellular membranes of the spine apparatus (Fig. $1 D, E$ ). Quantitative analysis of gold particles at synapses revealed a peak centered within $10 \mathrm{~nm}$ of the postsynaptic membrane and confirmed similar labeling efficiency of both presynaptic and postsynaptic sites (Fig. 1 F) (419 PEG particles, 111 synapses, 4 grids, all PEG particles counted). This distribution highlights that the postsynaptic pool of neurexins is of a significant size and that the level of neurexin immunoreactivity is similar in the presynaptic and postsynaptic compartments. When we scored synapses according to the presence of PEG labeling exclusively in the presynaptic or postsynaptic side or labeling in both synaptic compartments, we observed that $35 \%$ showed labeling on both sides, whereas $26 \%$ were labeled exclusively presynaptically and 39\% were labeled exclusively on the postsynaptic side (total of 163 synapses from two independent experiments). In this analysis, only structures 
labeled with a minimum of three PEG particles were considered positive. However, the conclusions did not change even when all PEG-positive structures were scored (total of 205 labeled synapses, 27\% presynaptic only, $34 \%$ postsynaptic only, $39 \%$ both sides labeled). These findings show that endogenous neurexin proteins are concentrated at synapses in vivo and that a major pool of endogenous neurexins localizes to the postsynaptic compartment.

The pan-neurexin antibodies do not allow any conclusions regarding the specific neurexin isoforms that are targeted to presynaptic and/or postsynaptic sites. To specifically investigate the subcellular targeting of $\operatorname{NRX} 1 \beta 4(+)$ (a neurexin-1 $\beta$ splice isoform containing an insertion in site 4), we generated transgenic mice expressing a GFP-tagged form of the protein under control of the neuron-specific Thy1.2 promoter (Fig. $2 A$ ). In previous studies, we confirmed that incorporation of GFP into the juxtamembrane domain of neurexins does not significantly alter their intracellular transport and the ability to interact with neuroligins in vitro (data not shown).

As demonstrated in previous studies (Caroni, 1997; Feng et al., 2000), expression from the Thy1.2 promoter resulted in labeling of different subsets of neurons in the different mouse lines (data not shown). The NRX1 mRNA overexpression level in the transgenic mice was estimated by quantitative PCR using primers specific for the $4(+)$ variant. Compared with endogenous NRX1, the mRNA level was estimated to be increased less than sevenfold. Considering that NRX1-NRX3 genes are coexpressed in most neurons, the overexpression compared with the total neurexin level is significantly lower than this. In all lines, we observed prominent labeling of axon tracts and synapserich areas (data not shown). One representative line was used for a more detailed anatomical analysis. In the hippocampus, prominent GFP-NRX1 $\beta 4(+)$ expression was observed in the dentate granule cells, so identified by their immunoreactivity to calbindin (Fig. 2 B). Immunohistochemistry with anti-GFP antibodies revealed prominent labeling of the mossy fiber projection to the CA3 field of the hippocampus as well as the inner molecular layer of the dentate gyrus, sites in which synapses with commissural axons of the association path are received (Fig. $2 B$ ). Under the same staining conditions, no significant labeling was observed in wild-type mice (supplemental Fig. S1 $D, E$, available at www.jneurosci.org as supplemental material). In the cortex, GFP-NRX1 $\beta 4(+)$ labeling was detected in neuronal cell bodies, especially of layer 5 pyramidal
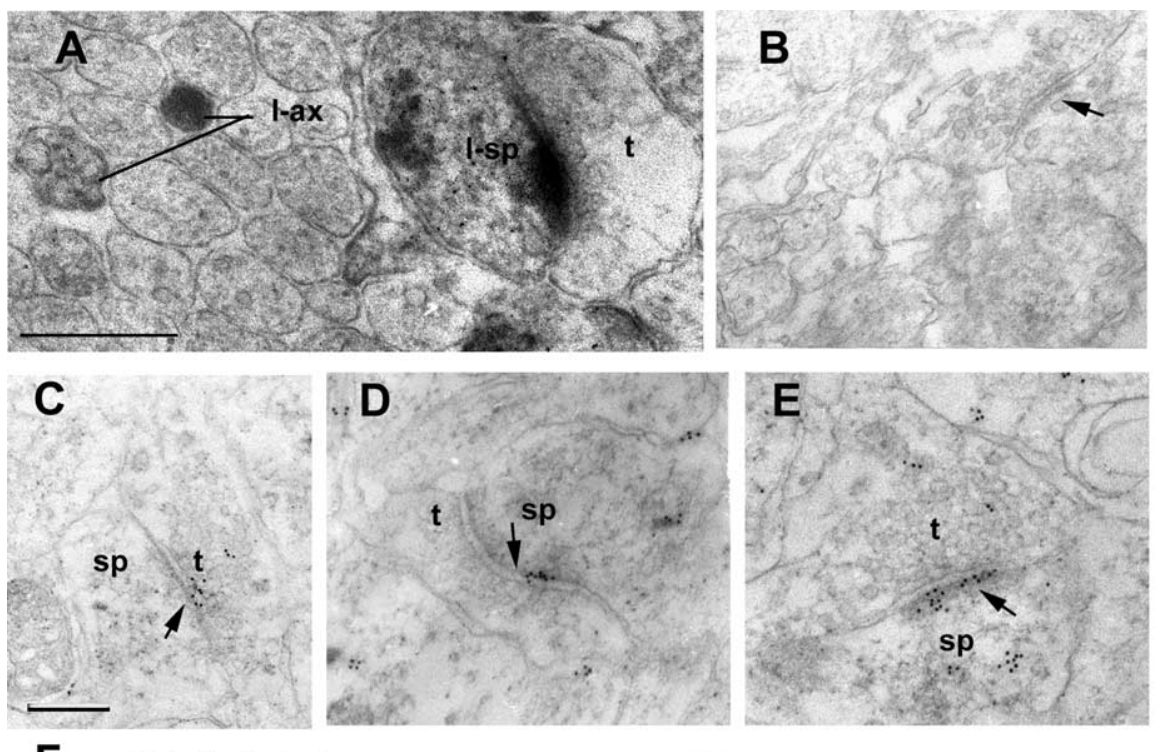

\section{$\mathbf{F}$



Figure 1. Ultrastructural localization of neurexins in $P 7$ and $P 8$ cerebral cortices and cerebellum of rats as visualized by the HRP-DAB and PEG immunolabels. Using a pan-neurexin antibody followed by HRP-DAB and PEG immunolabels, the variety of perisynaptic positions taken by neurexin is shown. $A, H R P-D A B$ revealed neurexin labeling within many axons of the molecular layer of P7 cerebellum, one example of which is shown here (I-ax). Immediately adjacent to I-ax is an example of dense immunolabeling that occurs along the postsynaptic membrane and intracellularly within spines (I-sp). In contrast, the axon terminal that is presynaptic to the labeled spine is unlabeled (t). Scale bar, $500 \mathrm{~nm}$ (also applies to $\boldsymbol{B}$ ). Arrows here and in all other panels point to the postsynaptic density. Tissue for this analysis was fixed with $4 \%$ paraformaldehyde. Subsequent to the immunocytochemical procedure, the vibratome sections were fixed using $1 \%$ glutaraldehyde, followed by $1 \%$ osmium tetroxide and counterstaining with $1 \%$ uranyl acetate. The light microscopic images of the vibratome section from which these ultrathin sections were sampled are shown in supplemental Figure S1 (available at www.jneurosci.org as supplemental material). $\boldsymbol{B}$, Vibratome section of P7 cerebellum taken semi-adjacent incubated using the same pan-neurexin antibody that was preabsorbed with the antigen. Immunolabeling was eliminated from spines and axons. $\boldsymbol{C}-\boldsymbol{E}$, Clusters of immunogold labeling achieved at the PEG stage occur discretely along the plasma membrane of synapses in the infragranular layers of P7 cerebral cortex. C shows an example of PEG particles at and near the presynaptic membrane of an axon terminal $(\mathrm{t})$ and in the cleft. $\boldsymbol{D}$ and $\boldsymbol{E}$ show clusters of PEG particles along the postsynaptic membrane and PSD of dendritic spines (sp) and the synaptic cleft. $\boldsymbol{E}$ shows additional PEG clustered along the spine apparatus and presynaptic terminal (t). Scale bar, $200 \mathrm{~nm}$ (also applies to $\boldsymbol{C}-\boldsymbol{E}$ ). $\boldsymbol{F}$, The PEG particle distribution was analyzed relative to synaptic junctions. PEG positions were measured as distance, in nanometers, from the postsynaptic membrane, and all PEG particles were counted in mutually exclusive bins $(0-10,10-20,20-30 \mathrm{~nm}$, etc.). These distances span six categories described to the left of the diagram as "Within Terminals," "At/Near Presynaptic Membrane," "At cleft," "At PSD," "Near PSD" (and along the postsynaptic membrane), and "Within Spines" (but away from the PSD). This analysis was based on 419 PEG particles that were associated with 111 labeled synapses showing clear presentation of the synaptic cleft. The labeled synapses were encountered across four grids.

neurons, and along their apical dendrites (Fig. 2C). These findings support a prominent localization of tagged NRX1 $\beta 4(+)$ in axon tracts and in synapse-rich areas of the cortex and hippocampus by light microscopy.

We next analyzed GFP-NRX1 $\beta 4(+)$ localization in layers 5 through 6 of the cortex, the CA3 field of the hippocampus, and the inner molecular layer of the dentate gyrus by immunoelec- 

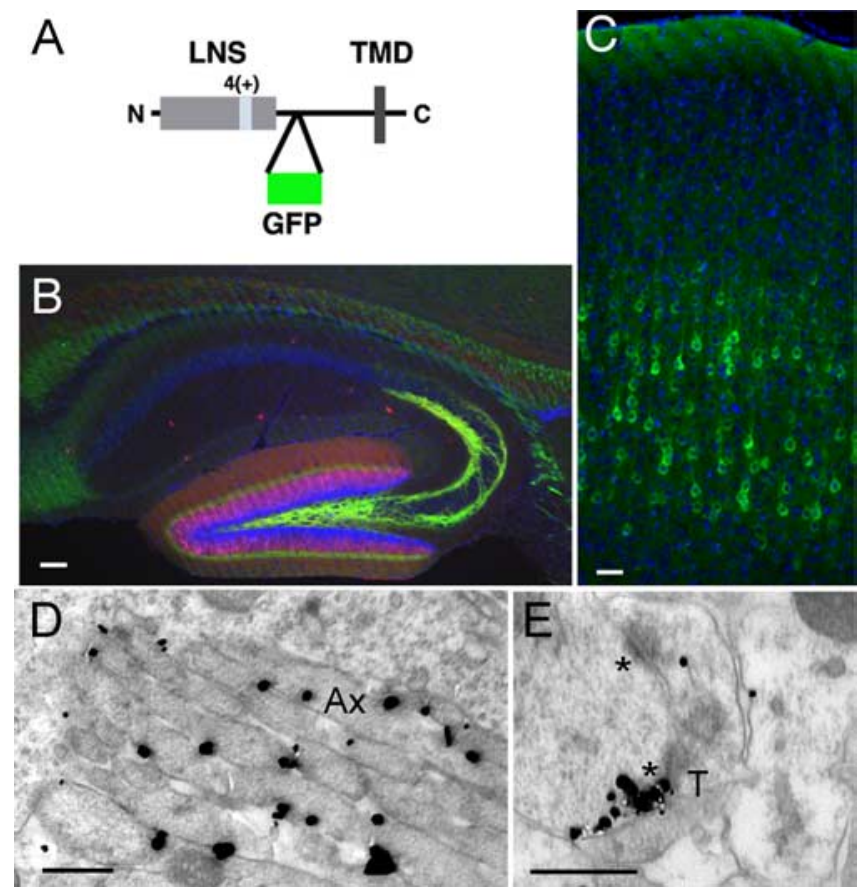

Figure 2. Epitope-tagged neurexin-1 $\beta$ is detected in axons and dendrites. $\boldsymbol{A}$, Schematic representation of GFP-tagged NRX1 $\beta 4(+)$ used to generate transgenic mice. The EGFP sequence was inserted into the extracellular stalk domain of neurexin. The insertion at splice site 4 is marked as $4(+)$, and the LNS domain and transmembrane domain (TMD) are marked. $\boldsymbol{B}$, Detection of GFP-NRX1 $\beta 4(+)$ (anti-GFP, green) in dentate granule cells at P10, triple stained for calbindin (red) and Hoechst (blue). Scale bar, $100 \mu \mathrm{m}$. C, Detection of GFP-NRX1 $\beta 4(+)-$ expressing pyramidal neurons (anti-GFP, green) in the cortex of P10 mouse brains. Nuclei are stained with Hoechst dye (blue). Scale bar, $100 \mu \mathrm{m}$. D, E, GFP-NRX1 $\beta 4(+)$ localization was probed by EM using anti-GFP and SIG as electron-dense labels for EM. $\boldsymbol{D}$ shows an example of labeling along the plasma membrane of axons (Ax) in the molecular layer of the dentate gyrus. Most of the labeling was in preterminal portions of axons, such as these. $\boldsymbol{E}$ shows an example of SIG particles clustered along the postsynaptic density (lower of two asterisks) that is postsynaptic to an axon terminal (T) in the molecular layer of the dentate gyrus. Scale bar, $500 \mathrm{~nm}$. No significant labeling was observed with the anti-GFP antibodies when wild-type tissue was probed (supplemental Fig. S1 B, available at www.jneurosci.org as supplemental material).

tron microscopy on P14 animals using anti-GFP antibodies followed by SIG labeling (Fig. $2 D, E$ ). Staining of tissue from wildtype animals revealed negligible labeling with anti-GFP antibodies (supplemental Fig. S1C, available at www.jneurosci. org as supplemental material), indicating that labeling for GFPneurexin obtained in tissue from transgenic animals was highly specific. As observed with the pan-neurexin antibodies, also the tagged NRX1 $\beta 4(+)$ protein was detected in axons (Fig. $2 D$ ) and dendrites (Fig. 2E). At the cell surface, we observed strongest immunoreactivity at the plasma membrane of axons ( $51 \pm 4$ and $55 \pm 6 \%$ of particles in cortex and hippocampal formation, respectively), followed by the plasma membrane of dendrites (11 \pm 2 and $17 \pm 3 \%$, respectively) (Table 1 ). At some synapses, prominent labeling was observed in presynaptic or postsynaptic compartments, directly at the active zone and postsynaptic density (Fig. 2E). In general, synaptic labeling was less frequently observed than nonsynaptic labeling. This might in part be attributable to reduced accessibility of the extracellular GFP epitope in the synaptic cleft compared with the pan-neurexin antibody that recognizes the cytoplasmic tail of neurexins. Regardless, these data reveal axonal and dendritic localization of the transgenically expressed GFP-tagged NRX1 $\beta 4(+)$ isoform and further suggest that neurexin proteins are not restricted to axons but can also found in dendrites and at some postsynaptic sites.
Postsynaptic neurexin expression alters neuroligin activity Previous work demonstrated that NL1 is selectively targeted to dendrites in which it is concentrated in the postsynaptic membrane (Song et al., 1999; Dresbach et al., 2004; Iida et al., 2004; Rosales et al., 2005). Our finding that neurexins are present at significant levels in dendrites raises the question whether its coexpression in the same membrane with NL1 might affect neuroligin function. To test this possibility, we examined whether cisexpressed NRX1 isoforms alter the ability of NL1 to stimulate presynaptic differentiation. Overexpression of NL1 in cultured hippocampal neurons leads to an increase in the density of synaptic vesicle clusters formed on the transfected cells (Dean et al., 2003; Prange et al., 2004; Chih et al., 2005; Sara et al., 2005) (Fig. $3 A)$. Cotransfection of NL1 expression vectors with cDNAs encoding NRX1 $\beta 4(-)$ and NRX1 $\beta 4(+)$ (isoforms lacking and containing an insertion in splice site 4 ) potently suppressed NL1induced synaptic vesicle clustering (Fig. $3 A, B$ ). In contrast, coexpression of EphB2, a postsynaptic receptor implicated in glutamatergic synapse formation (Dalva et al., 2000), did not alter $\mathrm{NL} 1$ activity in this assay (Fig. $3 B$ ). Some suppression activity was also observed for the NRX1 $\alpha 4(-)$ isoform, although this isoform was much less potent than the $\beta$-neurexins tested. Deletion of the extracellular LNS domain in NRX1 $\beta$, which represents the neuroligin binding site, resulted in a complete loss of the suppression activity (NRX $\Delta$ LNS) (Fig. $3 A, B$ ). Importantly, the loss of synaptic vesicle clustering was not attributable to reduced surface levels of the expressed NL1 protein on the transfected cells because quantitative analysis in nonpermeabilized cells confirmed comparable NL1 protein levels for most conditions. We only observed a slight reduction in NL1 expression in the cotransfection with NRX1 $\alpha 4(-)$ and EphB2 (Fig. 3C). However, NL1 levels were identical to control in the cells expressing NRX1 $\beta 4(-)$ and $4(+)$, the two isoforms with the most potent silencing activity. In summary, these findings reveal an unexpected new activity of $\beta$-neurexins in cultured hippocampal neurons.

\section{Direct regulation of neuroligin activity by neurexin in cis}

Postsynaptic $\beta$-neurexins might affect NL1 activity by either directly altering the function of NL1 or affecting other postsynaptic factors in hippocampal neurons. To test whether neurexins can directly alter neuroligin activity, we used a mixed culture assay in which NL1 expressed in non-neuronal cells is used to induce the assembly of presynaptic structures in axons (Scheiffele et al., 2000; Biederer and Scheiffele, 2007). As described previously, addition of HEK293 cells expressing NL1 to cultured hippocampal neurons induced the clustering of synaptic vesicles at cell-cell contact sites (Fig. 4A). Cotransfection of NRX1 $\beta 4(-)$ and to a lesser extent NRX1 $\beta 4(+)$ and NRX1 $\alpha 4(-)$ with NL1 inhibited this synaptogenic activity of NL1 (Fig. $4 A, B$ ). As observed for the neuronal coexpression, this inhibitory function of NRX1 $\beta$ required the LNS domain, and cotransfection of EphB2 did not alter NL1 function (Fig. $4 \mathrm{~B}$ ). None of the neurexin isoforms significantly altered surface density of NL1 in the transfected HEK293 cells (supplemental Fig. S2 A, available at www.jneurosci. org as supplemental material). This suggests that the inhibition of NL1 function by postsynaptic neurexins does not require other neuron-specific components of the postsynaptic apparatus and depends on the extracellular LNS domain of neurexin.

The simplest model for how postsynaptic neurexins might inhibit neuroligin activity is by interacting with neuroligins within the same membrane (in cis-), which might prevent transsynaptic interaction with axonal neurexin receptors. To test this model, we assayed binding of soluble recombinant neurexin to 
HEK293 cells expressing only NL1 or to cells that coexpress NL1 and NRX1 isoforms. Recombinant NRX1 $\beta 4(-)$ bound efficiently to NL1-expressing cells as detected by immunostaining for the Fc tag on the recombinant protein (Fig. 4C) (supplemental Fig. S2B, available at www.jneurosci.org as supplemental material). Cotransfection of NRX1 $\beta 4(-)$ and $\operatorname{NRX} 1 \beta 4(+)$ reduced binding to background levels, whereas cotransfection of NRX $1 \alpha 4(-)$ only slightly reduced NRX1 $\beta 4(-)$ binding (Fig. 4C). This suggests that cis-expression of NRX1 $\beta$ isoforms with NL1 in the same membrane can prevent NRX1 binding to NL1 in trans. Because expression of the NRX1 $\beta$ mutant lacking the LNS domain does not affect neurexin binding (Fig. 4C), this suppression requires the extracellular domain of neurexin and is likely mediated through direct cis-interactions with NL1.

We next tested whether cis-expressed neurexins can also alter the neurexinbinding capability of endogenous neuroligins in cultured hippocampal neurons. Compared with EGFP-expressing control cells, NRX1 $\beta 4(-)$-expressing neurons showed reduced binding of recombinant NRX1 $\beta 4(-)-$ Fc protein (Fig. 5A). In contrast, expression of NRX $\Delta$ LNS did not change NRX1 $\beta 4(-)-F c$ binding. Because the expression of endogenous neuroligins in hippocampal neurons might be altered by neurexin overexpression, we probed NRX1 $\beta$-expressing cells with a panneuroligin antibody (Fig. $5 B, C$ ) (for characterization of the antibody reagent, see supplemental Fig. S3 $A, B$, available at www.jneurosci.org as supplemental material). Surprisingly, NRX1 $\beta 4(-)$ expressing hippocampal neurons showed a fourfold upregulation of neuroligin immunoreactivity outlining the neuronal processes. Similar neuroligin upregulation was observed for the $\operatorname{NRX} 1 \beta 4(+)$ isoform but not for cells expressing NRX1 $\alpha 4(-)$ or the NRX $\Delta$ LNS mutant (Fig. $5 B$ ). Despite the dramatic increase in neuroligin level in the $\beta$-neurexinexpressing cells, NRX1 $\beta 4(-)-\mathrm{Fc}$ binding was reduced (Fig. $5 A$ ), suggesting that the neuroligin protein is not available for interaction with neurexin in trans. These findings confirm the inactivation of neuroligin function by cisexpressed neurexins and reveal an unexpected coupling between the expression of neuroligin and neurexin proteins.

The overexpressed neurexin proteins were detected in axons and dendrites. In dendrites, we observed some diffuse labeling along the plasma membrane but also punctate structures. Labeling with antibodies to EEA1, an early endosomal marker (Wilson et al., 2000), and PSD95, a component of the postsynaptic scaffold, revealed that subsets of HA-NRX1 $\beta 4(-)$ puncta colocal(Student's t test, $p<0.005$ )
Table 1. Subcellular distribution of GFP-NRX1 $\beta 4(+)$ in cortex and hippocampus of transgenic mice

\begin{tabular}{|c|c|c|c|c|c|}
\hline \multirow[b]{3}{*}{ Tissue } & \multicolumn{5}{|c|}{ \% SIG particles } \\
\hline & \multicolumn{2}{|l|}{ Axonal } & \multicolumn{2}{|l|}{ Dendritic } & \multirow{2}{*}{$\frac{\text { Axodendritic }}{\text { Contacts }}$} \\
\hline & Intracellular & Membranous & Intracellular & Membranous & \\
\hline P14 cortex & $11 \pm 2$ & $51 \pm 4$ & $19 \pm 3$ & $11 \pm 2$ & $8 \pm 2$ \\
\hline P14 hippocampal formation & $6 \pm 2$ & $55 \pm 6$ & $10 \pm 3$ & $17 \pm 3$ & $12 \pm 3$ \\
\hline
\end{tabular}

Sections containing the cerebral cortex and hippocampal formation were subjected to EM analysis after immunolabeling for GFP, the extracellular tag of transgenically expressed NRX1 $\beta 4(+)$, using SIG as the label. SIG particles were identified as residing in dendrites versus axons and at the plasma membrane cortical tissue, the number of SIG particles encountered was 501 , all of which were identified within 11 micrographs sampled randomly from the infragranular layers. For the hippocampus, $156 \mathrm{SIG}$ particles were encountered from 12 micrographs, taken from the molecular layer of the dentate gyrus. In cortex, all subcellular domains were identifiable. However, in the hippocampus, $19 \%$ of the SIG particles resided within subcellular profiles that were unidentifiable as a result of immaturity. The values shown represent percentages $\pm S E M$ in each subcellular domain. ANOVA revealed statistically significant differences in the group means $(p<0.00001)$, indicating highly specific and heterogeneous distribution of NRX1 $\beta 4(+)$ expression across the subcellular domains. Student's test revealed that this heterogeneity reflects significant enrichment of NRX1 $\beta 4(+)$ in axonal membranes $(p<0.00001)$. Specificity of labeling in dendritic membrane and the axodendritic junctional cleft were revealed by comparing SIG particle distribution between tissue of transgenic and wild-type mice

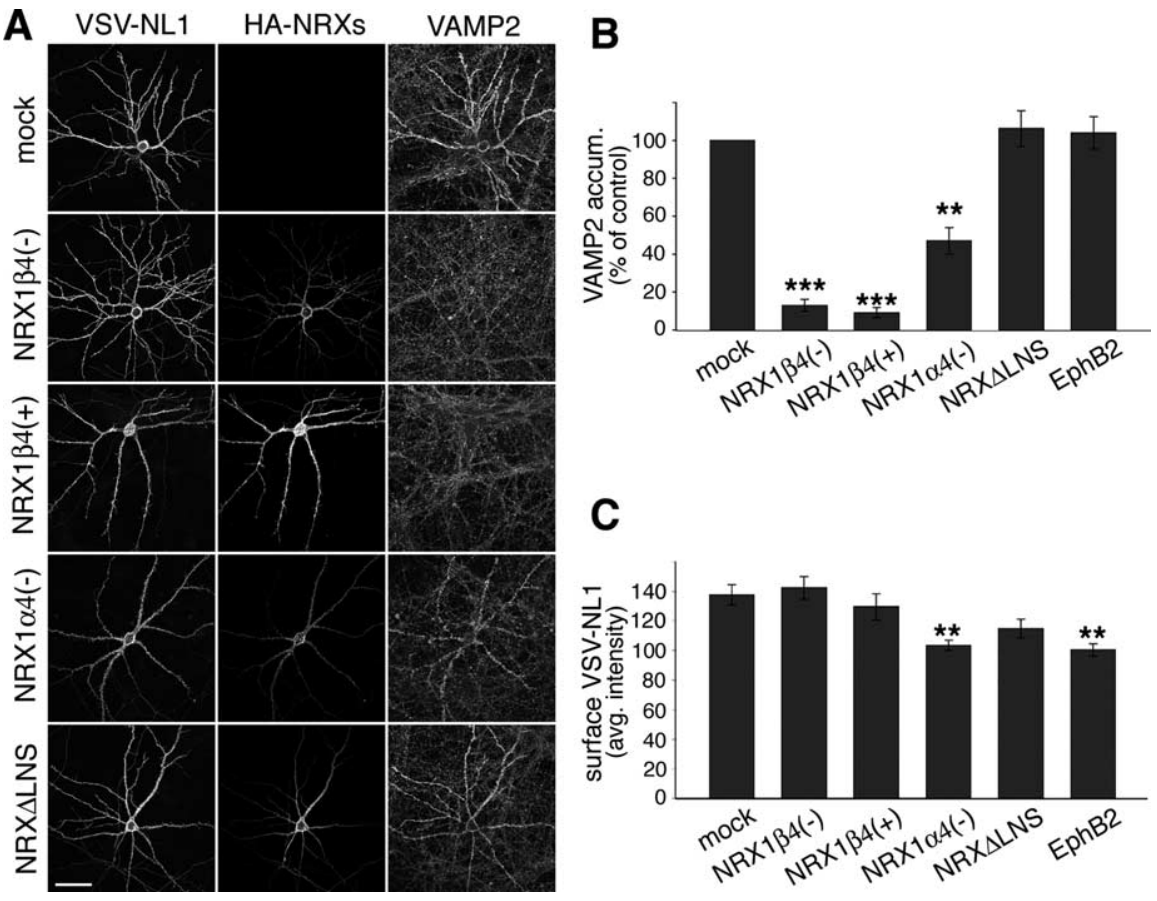

Figure 3. cis-expression of neurexins reduces synaptogenic activity of neuroligin-1 in hippocampal neurons. $\boldsymbol{A}$, Hippocampal neurons were cotransfected with VSV-epitope-tagged NL1 and different HA-epitope-tagged NRX1 expression constructs at 10 DIV and were analyzed $2 \mathrm{~d}$ later. For these experiments, the NL1 splice variant containing A and B splice insertions was used because this is the most abundant variant endogenously expressed in hippocampal neurons. Examples of transfected cells for the following conditions are shown: NL1 alone, NL1 plus NRX1 $\beta 4(-), N L 1$ plus NRX1 $\beta 4(+), N L 1$ plus NRX1 $\alpha 4(-)$, and NL1 plus NRX $\Delta$ LNS. Left column, Immunostaining for the VSV epitope in NL1; middle column, immunostaining for the HA epitope in the NRXs; right column, immunostaining for the synaptic vesicle marker VAMP2/synaptobrevin. The staining for NL and NRX isoforms was performed in nonpermeabilized cells, and images for all conditions were recorded with identical confocal acquisition settings. Scale bar, $50 \mu \mathrm{m}$. B, Quantification of VAMP2 immunoreactivity on the transfected cells, normalized to control cells overexpressing only NL1. Similar results were obtained in at least three independent experiments with at least 10 cells measured per condition in each experiment. Data from one experiment are shown (number of cells per condition, $n=10$; ${ }^{* *} p<0.01,{ }^{* * *} p<0.001$ ). $\boldsymbol{C}$, Quantification of average NL1 cell surface staining intensity in dendrites of neurons expressing NL1 alone or together with neurexin isoforms ( $n=10$ cells; ${ }^{* *} p<0.01$ ).

ized with EEA1 and PSD95, respectively (Fig. 6A1,A2). Colocalization with these markers was also observed when single confocal sections were examined at high magnification (supplemental Fig. S4, for characterization of the antibody reagent), and similar results were obtained with expression of HA-tagged NRX1 $\beta 4(+)$ and NRX1 $\alpha 4(-)$ (data not shown). Interestingly, in non-permeabilized, cells a more significant accumulation in spine heads was observed for $\operatorname{NRX} 1 \alpha 4(-)$ than for the $\beta$-neurexin isoforms (Fig. 6B1). This would be expected if high 


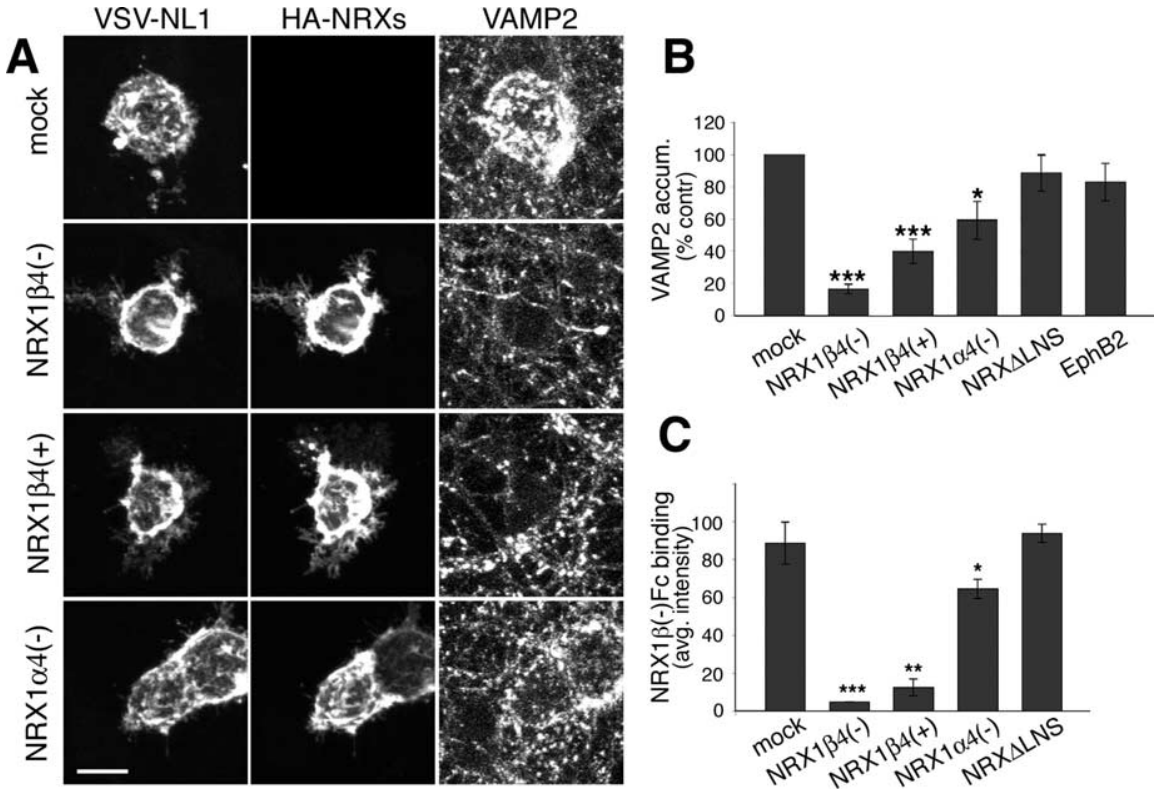

Figure 4. cis-expressed neurexins directly block synaptogenic activity of neuroligin-1. A, HEK293 cells cotransfected with NL1 and different NRX CDNAs were added to hippocampal neurons at $10 \mathrm{DIV}$, and cocultures were maintained for $2 \mathrm{~d}$. The following DNAs were transfected: NL1 alone (mock), NL1 plus NRX1 $\beta 4(-)$, NL1 plus NRX1 $\beta 4(+)$, and NL1 plus NRX1 $\alpha 4(-)$. Cultures were immunostained for the VSV epitope on NL1 (left), the HA epitope on NRXs (middle), and VAMP2 to detect synaptic vesicles (right). Scale bar, $10 \mu \mathrm{m}$. B, Quantification of the VAMP2 accumulation under the HEK293 cells, expressed as percentage of the signal obtained with cells expressing only NL1. Similar results were obtained in at least three independent experiments for at least 10 cells per condition in each experiment. Data from one experiment are shown $\left(n=10 ;{ }^{*} p<0.05,{ }^{* * *} p<0.001\right)$. The NL1 cell surface expression levels were measured by quantification of anti-VSV staining intensity on the transfected HEK293 cells (see Fig. S2A, available at www.jneurosci.org as supplemental material) $(n=10 ; p>0.05)$. C, Neurexin binding was quantified as the average NRX1 $\beta 4(-)-F($ staining intensity in the transfected HEK293 cells. Similar results were obtained in at least three independent experiments for at least 10 cells per condition in each experiment. Data from one experiment are shown $\left(n=10\right.$; ${ }^{*} p<$ $0.05,{ }^{* *} p<0.01,{ }^{* * *} p<0.001$ ). Images of the cell-binding experiments are shown in supplemental Figure S2 B (available at www.jneurosci.org as supplemental material).

levels of $\beta$-neurexins led to inactivation of endogenous neuroligins and destabilization of synaptic contacts. To directly test this possibility, we monitored the density of glutamatergic presynaptic vesicle clusters by immunostaining with antibodies to vGlut1 on the transfected cells (Fig. 6 B2). Quantitative analysis revealed a $35-50 \%$ reduction in the density of vGlut1 clusters on NRX1 $\beta$ expressing cells (Fig. 6B2,D), despite the fourfold increase in neuroligin expression levels (as shown in Fig. 5). In contrast, expression of NRX1 $\alpha 4(-)$ and the NRX $\Delta$ LNS mutant protein did not have a significant effect on the density of vGlutlpuncta $(p>0.05)$ (Fig. 6B2,D). These findings further support the model that postsynaptic $\beta$-neurexin proteins can silence the activity of neuroligins and compete for trans-synaptic interactions.

\section{Discussion}

Neurexins are a highly polymorphic family of neuronal cell surface receptors that are critical for synaptic function (Ushkaryov et al., 1992; Missler et al., 2003). However, the subcellular distribution of neurexin isoforms is unknown. In this study, we directly demonstrate that neurexins are localized to presynaptic release sites and postsynaptic densities. A series of cellular neurexinbinding and synapse assembly assays demonstrate that cisexpressed $\beta$-neurexins prevent trans-binding of $\beta$-neurexins to NL1, resulting in silencing of the synaptogenic activity of NL1. This provides a novel molecular mechanism for negative regulation of a synaptic adhesion molecule.

Previous work implicated neurexins primarily in presynaptic functions. The neurexin protein family was first identified as ax- onal receptors for $\alpha$-latrotoxin, the black widow spider toxin that induces massive synaptic vesicle fusion in the presynaptic terminal (Ushkaryov et al., 1992; Sugita et al., 1999). Subsequent studies showed that clustering of endogenous neurexin or epitope-tagged NRX1 $\beta$ in axons is sufficient for triggering presynaptic assembly (Dean et al., 2003). Finally, triple knockout mice lacking all $\alpha$-neurexins show defects in the functional coupling of presynaptic calcium channels to the synaptic release machinery (Missler et al., 2003). Our findings confirm localization of neurexins to presynaptic terminals and active zones but also uncovered an unexpected presence in the postsynaptic compartment.

The pan-neurexin antibodies used for our ultrastructural studies recognized all neurexin isoforms. Therefore, it still remains to be shown whether there is a molecularly distinct subset of neurexin isoforms that is predominantly enriched in dendrites or whether many neurexin isoforms are represented in both the presynaptic and postsynaptic compartments. Our finding that GFP-NRX1 $\beta 4(+)$ was abundant in dendritic endosomes and at the dendritic plasma membrane in vivo suggests that this isoform might be targeted at a significant level to dendrites. However, at this point, we cannot exclude that this is a result of mis-sorting under the overexpression conditions, and additional studies are required to probe whether there are neurexin isoforms that are exclusively sorted to axons or dendrites, respectively. It should be noted that, in contrast to neurexins, NL1 is strictly sorted to the somatodendritic domain by a cytoplasmic sorting signal and is excluded from axons (Dresbach et al., 2004; Iida et al., 2004; Rosales et al., 2005). This polarity of neuroligins imposes directionality on the synaptogenic activity of the heterophilic neuroligin-neurexin complex, even if neurexins are not exclusively localized to axons as previously assumed.

Our cell culture assays indicated that overexpression of NRX $1 \beta$ in dendrites reduces the density of presynaptic structures in cultured neurons, a phenotype that is similar to that observed after suppression of NL1 expression by RNA interference, dominant-negative mutants, or blocking of neuroligin function with recombinant neurexin-Fc proteins (Scheiffele et al., 2000; Graf et al., 2004; Prange et al., 2004; Chih et al., 2005, 2006; Levinson et al., 2005; Nam and Chen, 2005). Our mixed culture and neurexin binding assays suggest that cis-expressed neurexins inactivate NL1 by preventing the interaction with axonal neurexins in trans (see model in Fig. 6C). It should be noted that not all neurexin isoforms tested in our assays had a potent silencing activity, and most likely, some neurexin isoforms will have additional functions in the postsynaptic compartment that are unrelated to the silencing of neuroligins (Kattenstroth et al., 2004).

From a structural perspective, it is interesting that the requirements for the cis-silencing activity differ from binding in the trans configuration. In our assays, we observed similar cis-silencing of $\mathrm{NL1}$ by $\operatorname{NRX1} \beta 4(-)$ and $\operatorname{NRX} 1 \beta 4(+)$ splice isoforms. In con- 



Figure 5. $\beta$-Neurexin overexpression results in upregulation of neuroligins in cis. A, Quantification of NRX1 $\beta 4(-)-\mathrm{Fc}$ binding to control cells (EGFP), cells expressing NRX1 $\beta 4(-)$, and cells expressing NRX $\Delta$ LNS (binding is expressed as percentage of binding observed in control cells transfected with EGFP alone; $n=20$ cells; ${ }^{* *} p<0.01$ ). $\boldsymbol{B}$, Quantification of average pan-NL staining intensity on neurexin-expressing cells and control cells ("None") $(n=10 ; * * * 0.001)$. C, Hippocampal neurons were transfected with EGFP or different neurexin isoforms at $12 \mathrm{DIV}$ and analyzed $2 \mathrm{~d}$ later. Cells were coimmunostained with antibodies to the HA epitope on the transfected neurexins (top row) and with anti-pan-NL antibodies (bottom row). Images of the following transfection conditions are shown: NRX1 $\beta 4(-)$, NRX1 $\beta 4(+)$, and NRX $\Delta$ LNS. Note that the pan-NL antibody does detect endogenous neuroligin staining but that this staining is barely visible in these images. Because of the strong increase in endogenous neuroligin staining on the neurexin-expressing cells, confocal settings had to be set such that pan-NL staining in the nontransfected cells is very dim. For an image of endogenous NL staining in control cells, see Figure S3 (available at www.jneurosci.org as supplemental material). Scale bar, $20 \mu \mathrm{m}$.
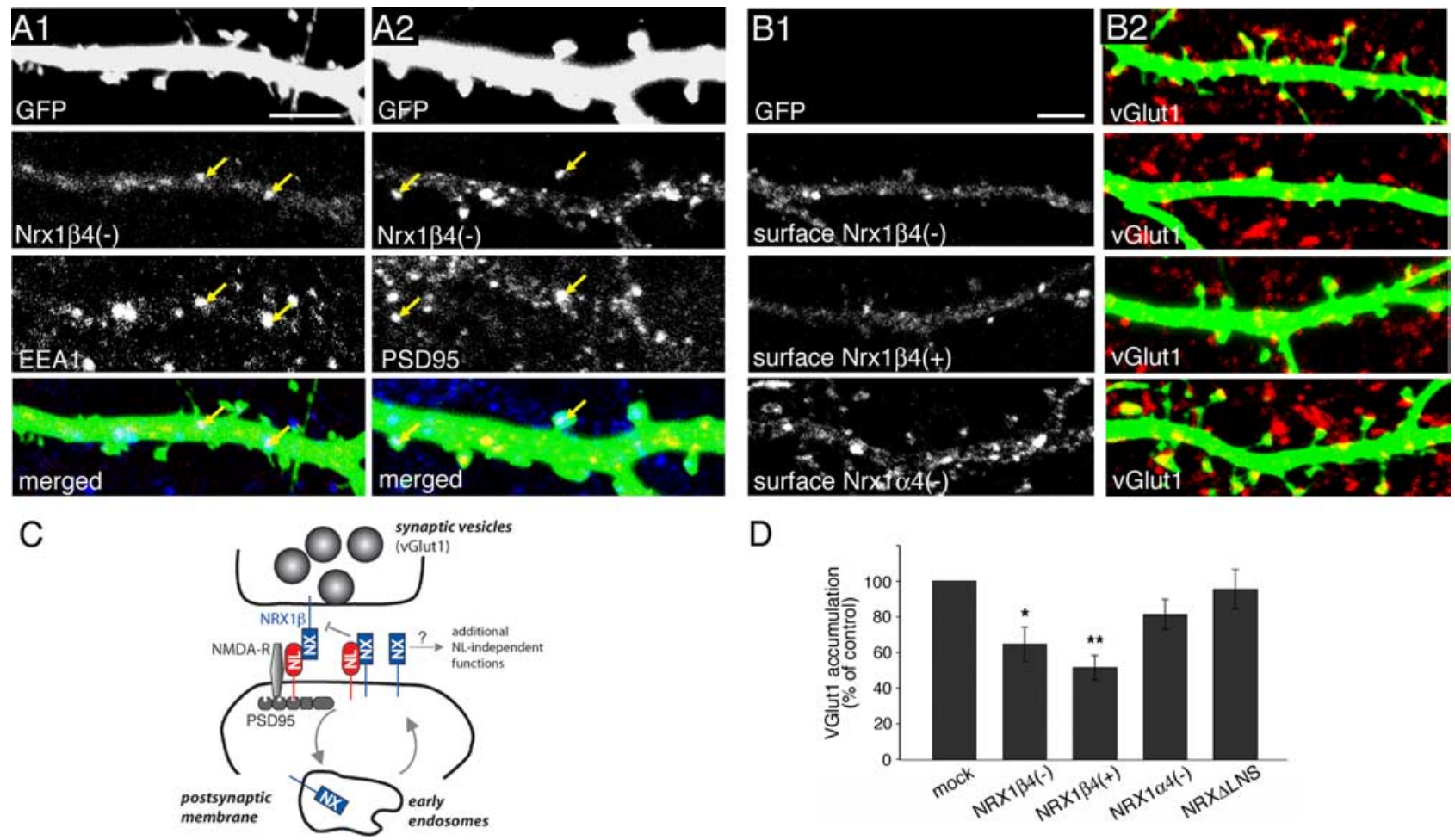

D

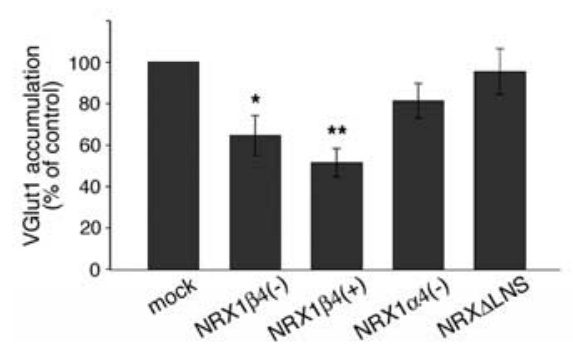

Figure 6. Dendritic neurexin expression reduces vGlut1 clustering and neurexin binding in dissociated hippocampal neurons. $\boldsymbol{A} 1, \boldsymbol{A 2}$, Dissociated hippocampal neurons were cotransfected with expression constructs for EGFP and HA-NRX1 $\beta 4$ (-) at 14-15 DIV and analyzed by immunohistochemistry at 17 DIV. Cells were triple immunostained with anti-GFP (green), anti-HA (red), and anti-EEA1 antibodies (A1, blue) or anti-PSD95 antibodies (A2, blue). Some punctate structures that are colabeled for the tagged neurexin and EEA1 or PSD95 are marked by arrows. Images shown are projected confocal image stacks, but colocalization was also observed when single optical sections were examined at high magnification (data not shown). Scale bar, $5 \mu$ m. B1, B2, Hippocampal neurons at 12 DIV were cotransfected with EGFP and with the different NRX isoforms and analyzed $2 \mathrm{~d}$ later. Before permeabilization, fixed cells were stained with anti-HA antibodies to detect cell surface distributions of HA-tagged NRX isoforms NRX1 $\beta 4(-), \operatorname{NRX1} \beta 4(+)$, and NRX1 $\alpha 4(-)$ (shown in B1). Subsequently, cells were permeabilized and glutamatergic presynaptic sites were labeled with antibodies to vGlut1 (red), and transfected cells were visualized by EGFP (green) that had been cotransfected with the NRX isoforms (shown in B2). Scale bar, $5 \mu \mathrm{m}$. C, Hypothetical model for postsynaptic $\beta$-neurexin function. Postsynaptic NL1 interacts trans-synaptically with NRX1 $\beta$. A pool of postsynaptic NL1 associates with NRX1 $\beta$ in the postsynaptic membrane in cis and therefore is not available for trans-synaptic binding. In dendrites, additional NRX1 $\beta$ molecules are present in early endosomal structures (EEA1-positive) from where they may recycle over the cell surface. $\boldsymbol{D}$, Quantification of vGlut1 cluster density on transfected cells (expressed as percentage of control cells transfected with EGFP alone; $n=10 ;{ }^{*} p<0.05$, ${ }^{* *} p<0.01$ ). 
trast, presence of the $4(+)$ insertion strongly reduces transbinding affinity of NRX1 $\beta$ for the major endogenous NL1 splice isoform and abolishes heterophilic adhesion with NL1expressing cells (Dean et al., 2003; Boucard et al., 2005; Chih et al., 2006). Compared with either $\beta$-neurexin isoform, NRX1 $\alpha 4(-)$ showed a reduced silencing activity that is consistent with the lack of high-affinity interaction between recombinant $\alpha$-neurexins and NL1AB (Boucard et al., 2005). Although additional work will be required to explain these differences, we consider it most likely that neuroligin-neurexin interactions in cis are mediated through an extracellular binding site that overlaps with the trans-interaction site but that is not structurally identical.

Recent studies on the EphA3-ephrinA5 complex have implicated cis-interactions in silencing signaling through this receptor-ligand complex during axon guidance (Yin et al., 2004; Carvalho et al., 2006). EphA3 and ephrinA5 physically associate with each other in a cis-manner. This interaction abolishes phosphorylation of EphA3 and the repulsive response of retinal axons to ephrinAs in trans. This suggests an interesting similarity in silencing the activity of an axon guidance receptor and a synaptic adhesion protein.

A surprising finding was the upregulation of endogenous neuroligin expression in cultured hippocampal neurons with increased $\beta$-neurexin levels (Fig. 5). Despite this upregulation, we observed a decrease in neurexin trans-binding to these cells, indicating that the cis-interactions were sufficient to silence the additional neuroligin protein. We tested whether neuroligin upregulation might represent a compensatory response to changes in neuronal activity in the neurexin-expressing cells. However, neuroligin upregulation was unchanged when sodium channeldependent action potentials were blocked with tetrodotoxin (Fig. $\mathrm{S} 3 \mathrm{C}$ ). Therefore, it is unlikely that homeostatic scaling mechanisms are responsible for neuroligin upregulation under these conditions. Regardless of the mechanism, our finding provides additional evidence for cis-coupling between neuroligin and neurexin functions in the dendritic compartment.

Silencing of neuroligin by postsynaptic neurexins might be used in several ways to regulate neuronal function. Postsynaptic neurexins may restrict the number or size of active neuroligin domains in the dendritic surface and thereby regulate synapse formation. A recent study indicated that nonsynaptic complexes of postsynaptic proteins including NL1 might be hotspots for the initiation of synapse formation (Gerrow et al., 2006). Axonal interactions with these NL1 puncta might be suppressed or weakened by interaction with postsynaptic neurexins in cis. Another possibility is that postsynaptic neurexins may dynamically modify the activity of neuroligin molecules in existing synapses. In such a model, neurexins could be delivered to individual synapses from dendritic endosomes in response to synaptic signaling. This could result in selective reduction of synapse size or function and ultimately provide a mechanism for synapse disassembly. Alternatively, postsynaptic neurexins could trigger a transient weakening of synaptic adhesion complexes that may enable structural remodeling during the maturation of synapses.

\section{References}

Aoki C, Miko I, Oviedo H, Mikeladze-Dvali T, Alexandre L, Sweeney N, Bredt DS (2001) Electron microscopic immunocytochemical detection of PSD-95, PSD-93, SAP-102, and SAP-97 at postsynaptic, presynaptic, and nonsynaptic sites of adult and neonatal rat visual cortex. Synapse 40:239-257.

Aoki C, Sekino Y, Hanamura K, Fujisawa S, Mahadomrongkul V, Ren Y, Shirao T (2005) Drebrin A is a postsynaptic protein that localizes in vivo to the submembranous surface of dendritic sites forming excitatory synapses. J Comp Neurol 483:383-402.

Benson DL, Colman DR, Huntley GW (2001) Molecules, maps and synapse specificity. Nat Rev Neurosci 2:899-909.

Biederer T, Scheiffele P (2007) Mixed-culture assays for analyzing neuronal synapse formation. Nat Protoc, in press.

Boucard AA, Chubykin AA, Comoletti D, Taylor P, Südhof TC (2005) A splice code for trans-synaptic cell adhesion mediated by binding of neuroligin 1 to alpha- and beta-neurexins. Neuron 48:229-236.

Caroni P (1997) Overexpression of growth-associated proteins in the neurons of adult transgenic mice. J Neurosci Methods 71:3-9.

Carvalho RF, Beutler M, Marler KJ, Knoll B, Becker-Barroso E, Heintzmann R, Ng T, Drescher U (2006) Silencing of EphA3 through a cis interaction with ephrinA5. Nat Neurosci 9:322-330.

Chih B, Engelman H, Scheiffele P (2005) Control of excitatory and inhibitory synapse formation by neuroligins. Science 307:1324-1328.

Chih B, Gollan L, Scheiffele P (2006) Alternative splicing controls selective trans-synaptic interactions of the neuroligin-neurexin complex. Neuron 51:171-178.

Dalva MB, Takasu MA, Lin MZ, Shamah SM, Hu L, Gale NW, Greenberg ME (2000) EphB receptors interact with NMDA receptors and regulate excitatory synapse formation. Cell 103:945-956.

Dean C, Scheiffele P (2004) Imaging synaptogenesis by measuring accumulation of synaptic proteins in transfected primary neurons. In: Imaging in neuroscience and development (Yuste R, Konnerth A, eds). Cold Spring Harbor, NY: Cold Spring Harbor Laboratory.

Dean C, Scholl FG, Choih J, DeMaria S, Berger J, Isacoff E, Scheiffele P (2003) Neurexin mediates the assembly of presynaptic terminals. Nat Neurosci 6:708-716.

Dresbach T, Neeb A, Meyer G, Gundelfinger ED, Brose N (2004) Synaptic targeting of neuroligin is independent of neurexin and SAP90/PSD95 binding. Mol Cell Neurosci 27:227-235.

Fannon AM, Colman DR (1996) A model for central synaptic junctional complex formation based on the differential adhesive specificities of the cadherins. Neuron 17:423-434.

Feng G, Mellor RH, Bernstein M, Keller-Peck C, Nguyen QT, Wallace M, Nerbonne JM, Lichtman JW, Sanes JR (2000) Imaging neuronal subsets in transgenic mice expressing multiple spectral variants of GFP. Neuron 28:41-51.

Gerrow K, Romorini S, Nabi SM, Colicos MA, Sala C, El-Husseini A (2006) A preformed complex of postsynaptic proteins is involved in excitatory synapse development. Neuron 49:547-562.

Goda Y, Davis G (2003) Mechanisms of synapse assembly and disassembly. Neuron 40:243-264.

Graf ER, Zhang X, Jin SX, Linhoff MW, Craig AM (2004) Neurexins induce differentiation of GABA and glutamate postsynaptic specializations via neuroligins. Cell 119:1013-1026.

Graf ER, Kang Y, Hauner AM, Craig AM (2006) Structure function and splice site analysis of the synaptogenic activity of the neurexin- 1 beta LNS domain. J Neurosci 26:4256-4265.

Ichtchenko K, Hata Y, Nguyen T, Ullrich B, Missler M, Moomaw C, Südhof TC (1995) Neuroligin 1: a splice site-specific ligand for beta-neurexins. Cell 81:435-443.

Iida J, Hirabayashi S, Sato Y, Hata Y (2004) Synaptic scaffolding molecule is involved in the synaptic clustering of neuroligin. Mol Cell Neurosci 27:497-508.

Kattenstroth G, Tantalaki E, Südhof TC, Gottmann K, Missler M (2004) Postsynaptic $\mathrm{N}$-methyl-D-aspartate receptor function requires alphaneurexins. Proc Natl Acad Sci USA 101:2607-2612.

Levinson JN, Chery N, Huang K, Wong TP, Gerrow K, Kang R, Prange O, Wang YT, El-Husseini A (2005) Neuroligins mediate excitatory and inhibitory synapse formation: involvement of PSD-95 and neurexin-1beta in neuroligin induced synaptic specificity. J Biol Chem 280:17312-17319.

Missler M, Zhang W, Rohlmann A, Kattenstroth G, Hammer RE, Gottmann K, Südhof TC (2003) Alpha-neurexins couple $\mathrm{Ca}^{2+}$ channels to synaptic vesicle exocytosis. Nature 423:939-948.

Nam CI, Chen L (2005) Postsynaptic assembly induced by neurexinneuroligin interaction and neurotransmitter. Proc Natl Acad Sci USA 102:6137-6142.

Peng J, Kim MJ, Cheng D, Duong DM, Gygi SP, Sheng M (2004) Semiquantitative proteomic analysis of rat forebrain postsynaptic density fractions by mass spectrometry. J Biol Chem 279:21003-21011. 
Phend KD, Rustioni A, Weinberg RJ (1995) An osmium-free method of epon embedment that preserves both ultrastructure and antigenicity for post-embedding immunocytochemistry. J Histochem Cytochem 43:283-292.

Prange O, Wong TP, Gerrow K, Wang YT, El-Husseini A (2004) A balance between excitatory and inhibitory synapses is controlled by PSD-95 and neuroligin. Proc Natl Acad Sci USA 101:13915-13920.

Rosales CR, Osborne KD, Zuccarino GV, Scheiffele P, Silverman MA (2005) A cytoplasmic motif targets neuroligin-1 exclusively to dendrites of cultured hippocampal neurons. Eur J Neurosci 22:2381-2386.

Russell AB, Carlson SS (1997) Neurexin is expressed on nerves, but not at nerve terminals, in the electric organ. J Neurosci 17:4734-4743.

Sara Y, Biederer T, Atasoy D, Chubykin A, Mozhayeva MG, Südhof TC, Kavalali ET (2005) Selective capability of SynCAM and neuroligin for functional synapse assembly. J Neurosci 25:260-270.

Scheiffele P (2003) Cell-cell signaling during synapse formation in the CNS. Annu Rev Neurosci 26:485-508.

Scheiffele P, Fan J, Choih J, Fetter R, Serafini T (2000) Neuroligin expressed in nonneuronal cells triggers presynaptic development in contacting axons. Cell 101:657-669.

Song JY, Ichtchenko K, Südhof TC, Brose N (1999) Neuroligin 1 is a postsynaptic cell-adhesion molecule of excitatory synapses. Proc Natl Acad Sci USA 96:1100-1105.

Sugita S, Khvochtev M, Südhof TC (1999) Neurexins are functional alphalatrotoxin receptors. Neuron 22:489-496.

Ushkaryov YA, Petrenko AG, Geppert M, Südhof TC (1992) Neurexins: synaptic cell surface proteins related to the alpha- latrotoxin receptor and laminin. Science 257:50-56.

Varoqueaux F, Aramuni G, Rawson RL, Mohrmann R, Missler M, Gottmann K, Zhang W, Südhof TC, Brose N (2006) Neuroligins determine synapse maturation and function. Neuron 51:741-754.

Waites CL, Craig AM, Garner CC (2005) Mechanisms of vertebrate synaptogenesis. Annu Rev Neurosci 28:251-274.

Wilson JM, de Hoop M, Zorzi N, Toh BH, Dotti CG, Parton RG (2000) EEA1, a tethering protein of the early sorting endosome, shows a polarized distribution in hippocampal neurons, epithelial cells, and fibroblasts. Mol Biol Cell 11:2657-2671.

Yamagata M, Sanes JR, Weiner JA (2003) Synaptic adhesion molecules. Curr Opin Cell Biol 15:621-632.

Yin Y, Yamashita Y, Noda H, Okafuji T, Go MJ, Tanaka H (2004) EphA receptor tyrosine kinases interact with co-expressed ephrin-A ligands in cis. Neurosci Res 48:285-296. 